\title{
Mask Work-Translating Lessons Learned in Drama School to Conversations on the Medical Wards
}

\author{
Bernard Landry-Wegener, M.D. ${ }^{1,2}$ (D) \\ 'Johns Hopkins University School of Medicine, Baltimore, MD, USA; ${ }^{2}$ Baltimore, USA.
}

J Gen Intern Med 36(10):3215-6

DOI: $10.1007 / \mathrm{s} 11606-021-06991-3$

(c) Society of General Internal Medicine 2021

$\mathrm{C}$ ommunication skills are essential for physicians and are included by the American College of Graduate Medical Education (ACGME) as one of the six core competencies for residency training. ${ }^{1}$ While working as a professional musical theatre actor and dancer, I saw the impact that communication skills can have on the patient-physician relationship firsthand. Throughout my short career, I ended up in several orthopedics clinics. The sports paraphernalia on the walls always made me feel self-conscious for expressing my athleticism with ballet slippers rather than cleats. At each visit, the orthopedist would quickly enter the exam room and hunch over the affected joint, focusing their entire physicality on it rather than me. My entire presentation was simplified to a brace and a physical therapy referral, when all I cared about was how the injury affected my ability to express myself artistically and stay employed.

After pivoting from musical theatre to a career in internal medicine, I found myself on the other side of the patientphysician relationship. During intern year, I ended up developing a repertoire of short monologues in response to common complaints and situations I faced on the wards. A busy call would predispose me to string these together into rigid interactions that technically covered all the necessary components of a patient consultation, but probably left my patients feeling just as removed from our relationship as I did in those orthopedic clinics.

A formulaic approach to patient interactions is common in medical education. Current communication skill trainings tend to focus on granular techniques to be used in a 2-way patientphysician conversation, rather than on the more general concept of relationship development. ${ }^{2}$ I have always seen this approach as lacking and in residency found myself relying on my drama training as a tool improve my communication skills, rather than on the lessons I learned in medical school.

Received April 24, 2021

Accepted June 16, 2021

Published online July 13, 2021
My undergraduate degree is a Bachelor of Fine Arts in musical theatre from a Midwest conservatory. There I learned that theatre is the portrayal of the human experience on stage. This realism is predicated on the actors' ability to convince the audience that the relationships onstage are genuine and that the actors are experiencing the events of the play along with the audience for the first time. To do this, actors must be able to understand their character's wants and needs, recognize how their physicality is outwardly perceived, and listen to their scene partner, even though they already know what they are going to say. I now see that these three skills translate directly to the empathy, non-verbal communication skills, and presence I strive for in both my professional and patient relationships.

As a senior resident, I now use these drama principles to teach others. One such example involved a 51-year-old grandmother with metastatic breast cancer, just discharged after undergoing surgery for spinal cord compression. She was admitted 1 week later with a large pleural effusion. The cytopathology eventually resulted as malignant, worsening an already grim prognosis. Because of the strong rapport the intern following her case had built with her, I felt it would be appropriate for the intern to deliver the news. When I asked her about her approach to difficult conversations, she responded with the familiar SPIKES mnemonic from her medical school studies.

This strategy is a popular six-step approach to breaking bad news to patients. ${ }^{3}$ The steps include ensuring the right setting for the consultation, "assessing patient's perceptions," making sure they are ready for the new information, breaking the news, educating the patient, and exhibiting empathy before summarizing the encounter. It is purposefully formulaic, with the authors comparing breaking bad news to other clinical scenarios like the management of diabetic ketoacidosis. For example, expressing empathy is simplified to the physician connecting "[the patient's] emotion with the reason for the emotion" using a short phrase such as "I can see how upsetting this is for you."

In discussing how the intern and I could apply this "checklist," we realized that it did not offer us enough guidance for our patient interaction. Instead, I offered the intern guidance on how I would approach this difficult conversation based on drama training. We talked about our patient's "backstory": the patient's isolation due to strict visitor restrictions fueling her anxiety. We identified the unavoidable obstacles of our 
"scene": the use of a Spanish translator changing the tempo of the conversation. Lastly, we discussed how our mask and face shield would impact our ability to connect.

Universal masking has drastically changed clinical communication in the hospital, with some arguing that mask wearing should continue beyond COVID-19 herd immunity citing the reduced rates of transmission of other respiratory viral illnesses and the unclear longevity of the protection granted by COVID-19 immunization. ${ }^{4}$ PPE deprives us of the non-verbal facial cues we are all accustomed to, forcing us to fill in the bottom half of someone's face with our presumed perception of their emotional state. Luckily, there is a drama correlative for this "mask work" that I could use to coach the intern with as well.

French acting teacher, Jacque Copeau (1879-1949), took the emotive theatrical masks of the ancient Greeks and turned them into a neutral face covering. His students would wear an expressionless mask covering with only their eyes showing in acting classes to force them to focus on how their physicality and spatial relationships impacted the emotion they wished to convey: "The mask aims to remove from the students the temptation to 'act' and return them to a state of intuitive understanding based on simple physical engagement with the world around them.".5

When I practiced "mask work" in my acting classes at the conservatory, I saw how the audience was forced to turn their attention elsewhere to determine my character's emotional reality. Things like body posture and the way I read the line took on more importance and could change the audience's perception of me from kind to condescending. I also could not control which part of my performance each audience member used to cast their judgment. I learned to be intentional and focused with my characterizations on stage.

Back in the work room, the intern and I discussed all the ways we could use our physicality and vocal tone to express empathy, and then entered the patient room to apply these lessons. The intern sat with the patient right away, something we all too often forgo. ${ }^{6}$ She leaned into the conversation with both feet on the floor rather than closing off her physicality by slouching in a chair with legs crossed. Her posture projected confidence, receptiveness, and ease. Even though the patient could not understand the words she said, she spoke in a calming tone. As the interpreter translated each sentence and she watched the patient's physicality react, she remained in the moment and responded accordingly. When the patient fell back in the chair at the realization that the cancer had invaded another place in her body, the intern leaned in and offered her a hand. She allowed for silence. This let the patient's emotional reaction fill the room instead of the intern's voice. The scene was not a happy one, but the humanity that existed between them was beautiful, nonetheless.
This patient interaction is only one of the many times I have found my drama training useful as a physician educator, and I am not alone. A recent scoping review on the humanities in medical education identified 70 articles describing educational interventions using theatre and drama. ${ }^{7}$ Additional explorations are needed to establish what learning objectives are best suited for drama-based interventions and the best way to implement them. These studies should pay special attention to introverted learners, as there is concern that they may be less suited for such inherently interactive curricula.

Given the improved outcomes patients of providers with better communication skills enjoy, we need to ensure that our approach to clinical interactions is applicable to the current landscape of health care delivery. ${ }^{1}$ The COVID-19 pandemic has been a striking example of how quickly that landscape can change. From my viewpoint as an actor, physician, and medical educator, drama training is a useful educational tool to provide the clinician with the skills needed for patientcentered communication today, and in the face of whatever may come next.

Corresponding Author: Bernard Landry-Wegener, M.D.; Baltimore, USA

\section{Declarations:}

Conflict of Interest: The author declares that he does not have a conflict of interest.

\section{REFERENCES}

1. Chou CL. Communication Rx: Transforming Healthcare through Relationship-Centered Communication. McGraw-Hill; 2018.

2. Csörsz I, Molnar P, Csabai M. Medical students on the stage: An experimental performative method for the development of relational skills. Med Teach 2011;33(9):e489-e494. https://doi.org/10.3109/0142159X. 2011.599449

3. Baile WF, Buckman R, Lenzi R, Glober G, Beale EA, Kudelka AP. SPIKES-A Six-Step Protocol for Delivering Bad News: Application to the Patient with Cancer. Oncologist 2000;5(4):302-311. https://doi.org/10. 1634/theoncologist.5-4-302

4. Mermel LA. The future of masking. Infect Control Hosp Epidemiol. Published online January 28, 2021:1-1. https://doi.org/10.1017/ice. 2020. 1439

5. Evans M. Jacques Copeau. First edition reissued in 2017. Routledge; 2017.

6. Merel SE, McKinney CM, Ufkes $\mathbf{P}$, Kwan AC, White AA. Sitting at patients' bedsides may improve patients' perceptions of physician communication skills: Physicians' Posture at Patients' Bedside. J Hosp Med 2016;11(12):865-868. https://doi.org/10.1002/jhm.2634

7. Moniz T, Golafshani M, Gaspar CM, et al. How Are the Arts and Humanities Used in Medical Education? Results of a Scoping Review. Acad Med. 2021; Publish Ahead of Print. https://doi.org/10.1097/ACM. 0000000000004118

Publisher's Note: Springer Nature remains neutral with regard to jurisdictional claims in published maps and institutional affiliations. 